Chemical Physics 136 (1989) 201-211

North-Holland, Amsterdam

\title{
INTRAMOLECULAR PROTON TRANSFER AND TUNNEL EFFECTS IN THE METASTABLE TRIPLET STATES OF 2-(2'-HYDROXYPHENYL)BENZOXAZOLE STUDIED BY MICRO- AND NANOSECOND LASER FLASH PHOTOLYSIS
}

\author{
K.H. GRELLMANN, A. MORDZIŃSKI ' and A. HEINRICH \\ Max-Planck-Institut für Biophysikalische Chemie, Abteilung Spektroskopie, Am Fassberg, D-3400 Göttingen, FRG
}

Received 18 January 1989

\begin{abstract}
The enol-keto tautomerism of 2-(2'-hydrophenyl)benzoxazole (HBO) in its metastable triplet states has been studied in fluid, non-polar solution. After laser flash excitation the keto triplet state is populated with high efficiency. The establishment of a ketoenol equilibrium was observed between 55 and $220 \mathrm{~K}$. At low temperatures the rate of this reaction is determined by tunnel effects. The barrier height of the proton transfer is in the triplet state much larger than in the singlet state.
\end{abstract}

\section{Introduction}

More than 30 years ago Weller published his now classic paper [ 1 ] on excited state intramolecular proton transfer (ESIPT) in salicylic acid. His work triggered research on this subject in many laboratories. A selection of more recent papers and reviews is listed in refs. [2-18]. With the advent of fast nano- and picosecond pulse techniques the elementary steps of the ESIPT reaction have been investigated more recently [19-24]. These studies are almost entirely concerned with ESIPT in the singlet manifold. Very little is known about the role of triplet states in such reactions.

We have recently investigated $[25,26]$ the photophysical properties of 2-(2'-hydroxyphenyl)benzoxazole (HBO) in non-polar solvents. Depending on its electronic state, HBO exists either as enol (E) or keto ( $\mathrm{K}$ ) tautomer (see fig. 1). It is well known [27] that in the excited state the proton transfer ${ }^{1} \mathrm{E}^{*} \rightarrow{ }^{1} \mathrm{~K}^{*}$ takes place very rapidly in the picosecond time range, making the lifetime of ' $E$ * very short and its fluorescence quantum yield immeasurably small. The lifetime of the electronically excited keto tautomer, ${ }^{1} \mathrm{~K}^{*}$, is considerably longer and determined by a thermally activated radiationless decay process (rate constant

\footnotetext{
1 Permanent address: Institute of Physical Chemistry, Polish Academy of Sciences, Warsaw, Poland.
}

$k_{\mathrm{d}}$ ), the emission of a strongly Stokes-shifted fluorescence $\left(k_{\mathrm{f}}\right)$ and by intersystem crossing ${ }^{1} \mathrm{~K}^{*} \rightarrow{ }^{3} \mathrm{~K}^{*}$ $\left(k_{\mathrm{st}}\right)$. At higher temperatures the thermally activated decay process $\left(k_{\mathrm{d}}\right)$ predominates, but at lower temperatures the fluorescence and intersystem crossing yields ( $\Phi_{\mathrm{f}}$ and $\Phi_{\text {isc }}$ ) increase strongly to a constant level which is reached at about $150 \mathrm{~K}$ [25]. Since below this temperature the sum of the two yields is most probably unity and $\Phi_{\mathrm{f}}(150 \mathrm{~K})=0.36[28]$, the triplet yield is very high. Therefore, $\mathrm{HBO}$ is a compound which is very well suited for studying the proton transfer process in the triplet manifold, because after the population of the triplet state ${ }^{3} \mathrm{~K}^{*}$, proton backtransfer takes place, yielding the enol triplet state ${ }^{3} \mathrm{E}^{*}$.

Recently, we have shown [26] that the two triplet states are in equilibrium. They both phosphoresce in fluid solution in distinctly different wavelength regions. The intensity ratio of this dual phosphorescence does not depend on the temperature as long as the solvent is fluid. (In glassy solutions the situation is more complicated [29].) We concluded from this observation that the two triplet states are iso-energetic. This fortunate (and presumably fortuitous) coincidence made it possible [26] to deduce with good accuracy from the absorption, fluorescence and dual phosphorescence spectra of HBO the energy levels of the Förster cycle as shown in fig. 1.

In the present paper we wish to report in greater detail flash photolytic data on the triplet states ${ }^{3} \mathrm{E}^{*}$ 


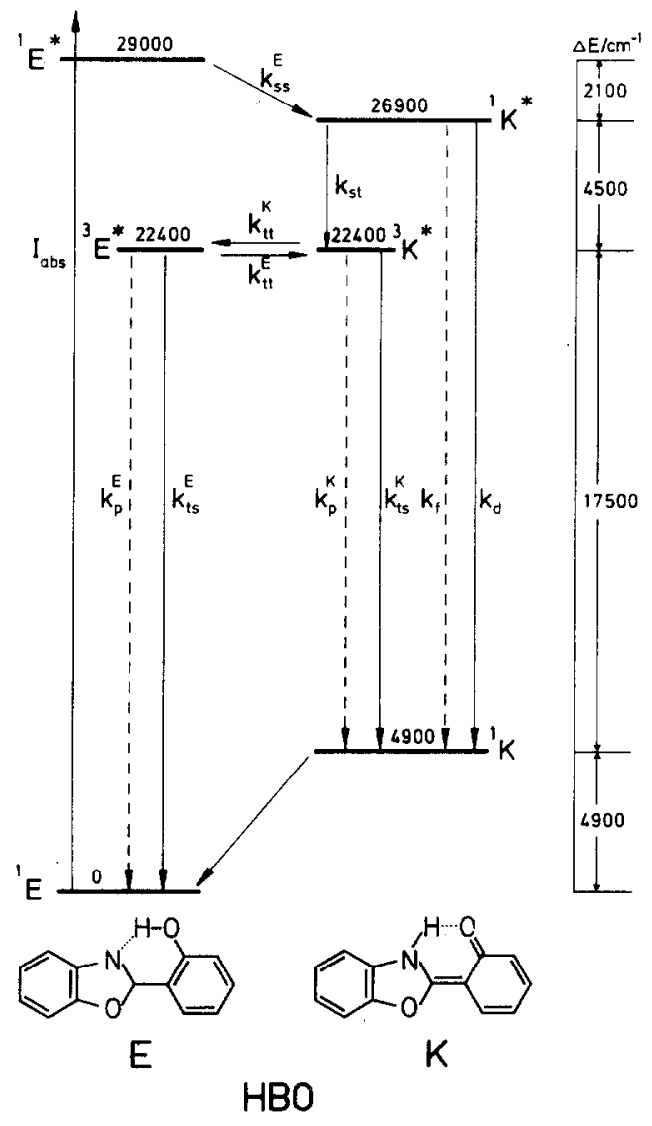

Fig. 1. Energy levels of the enol (E) and keto (K) tautomer of $\mathrm{HBO}$. The numbers are energies in wavenumbers $\left(\mathrm{cm}^{-1}\right)$ and are based on the results of ref. [26].

and ${ }^{3} \mathrm{~K}^{*}$ and discuss the kinetic results in view of the reaction scheme depicted in fig. 1 .

\section{Experimental}

\subsection{Solvents and compounds}

2-(2'-hydrophenyl) benzoxazole (HBO) purchased from EGA was recrystallized from $n$-hexane and further purified by column chromatography on Silicagel G (Merck), repeated vacuum sublimation and finally by zone melting. The final product was colorless and had a sharp melting point at $124.2^{\circ} \mathrm{C}$ (uncorrected). A few miligrams were further puri- fied by HPLC. This sample gave the same results as the zone refined compound.

The solvents methylcyclohexane (MCH) (Fluka), 2-methylpentane (MP) (Jansen), iso-pentane (IP) (Fluka) and cyclopentane (CP) (UVASOL, Merck) were purified immediately before use on a silica(Woelm 100-200 active)-aluminum oxide (Woelm B, Super 1, W 200) column. $\mathrm{CH}_{3} \mathrm{OD}(>99 \%$ D, UVASOL Merck) from a freshly opened bottle was used as received.

\subsection{Degassing and drying}

For degassing and drying we employ a greaseless vacuum line with a small turbo molecular pump. The flash cell assembly is attached to the vacuum line with indium O-rings $(1 \mathrm{~mm}$ ). (The use of indium is, in the long run, inexpensive because the used indium gaskets can be molten under nitrogen into a small bar and then again pressed into $1 \mathrm{~mm}$ threads, like sodium.) To avoid handling of $\mathrm{HBO}$ on a balance, we stuff micropipettes $(2-10 \mu \mathrm{l})$ to a certain height (1$2 \mathrm{~mm}$ ), cut off the rest of the pipette and place the part containing $\mathrm{HBO}(\approx 10 \mathrm{~mm})$ in a little capillary, which is sealed under nitrogen and which can later be broken in the storage vessel of the cell assembly with a magnetically actuated hammer. With some experience, it is amazingly easy to fill the micropipette quite reproducibly with fractions of a milligram of $\mathrm{HBO}$. As long as the capillary is sealed, the cell assembly can be dried under vacuum vigorously with a hot-air gun. During this drying procedure the solvent is kept in a second storage vessel at liquid-nitrogen temperature. This storage vessel is separately attached to the vacuum line and can be closed by a greaseless valve. It contains liquid $\mathrm{Na}-\mathrm{K}$ alloy and a magnetic stirrer. At room temperature, the solvent is stirred for several minutes with the $\mathrm{Na}-\mathrm{K}$ alloy and then distilled into the storage vessel of the cell assembly. After breaking the capillary and 6-7 freeze-pump-thaw cycles, the cell assembly is sealed off under vacuum. Besides the small storage vessel, the cell assembly consists usually of a $10 \mathrm{~mm} \times 10 \mathrm{~mm}$ fluorescence cell, a cell with a rectangular cross section of $10 \mathrm{~mm} \times 4$ $\mathrm{mm}$ and $100 \mathrm{~mm}$ optical pathlength for conventional flash experiments, and a similar cell with $20 \mathrm{~mm}$ optical path length for the laser flash experiments.

Deuteration. For experiments with DBO the capil- 
lary technique could not be used. We first degassed and dried $5 \mathrm{ml}$ of the solvent mixture IP/CP (1:1) in a special storage vessel $(A)$, which was equipped with a break-seal. After sealing off from the vacuum line, A was sealed onto the cell assembly, which consisted of two additional storage vessels ( $B$ and $C$ ), a $20 \mathrm{~mm}$ laser flash cell and a magnet to open the breakseal of A. A large excess of HBO (1 mg) was placed into the storage vessel $B$ and dissolved in $1 \mathrm{ml}$ $\mathrm{CH}_{3} \mathrm{OD}$. Then the assembly was quickly attached to the vacuum line, the solution degassed, the methanol distilled into vessel $C$ and $C$ sealed off from the vacuum line. After careful drying of the glassware with hot air and of the solid DBO with a water bath kept at $60^{\circ} \mathrm{C}$ (whereby a small fraction of DBO may be lost), the break-seal was opened and the solvent distilled from $\mathrm{A}$ into vessel $\mathrm{B}$ and again dried over $\mathrm{Na}-$ $K$. (For easier handling of the cell assembly, A was sealed off, while the solvent was kept in the Na-K vessel at $77 \mathrm{~K}$ and the solid $\mathrm{HBO}$ at room temperature in B.) The proper concentration of the solution was afterwards adjusted by pooring a fraction of the concentrated solution from vessel $B$ into the flash cell and by diluting it with the distilled rest of the solvent. The excess DBO remained as a solid in vessel $B$.

\subsection{Flash apparatus}

The laser flash experiments were carried out with an exciplex laser (Lambda Physik EMG 500) using the $\mathrm{KrF}$ line $(248 \mathrm{~nm}$, pulse width $10 \mathrm{~ns}$, laser energy $100 \mathrm{~mJ}$ ). The $10 \mathrm{~mm} \times 20 \mathrm{~mm}$ laser beam is focused with a cylindrical quartz lens to an area of $1-5$ $\mathrm{mm} \times 20 \mathrm{~mm}$ in the middle of the flash cell. The monitoring light from a pulsed $150 \mathrm{~W}$ Osram XBO lamp traverses the cell at right angles to the excitation beam. To match the level of the monitoring light beam with the excited area, the cylindrical lens can be moved a few millimeters vertically. The cell is housed in a copper block which is attached to a helium closedcycle cooling system (Air Products Displex System CSW-202) with a home made [30] top-loading unit. The temperature can be varied between 15 and 300 $\mathrm{K}$ with an accuracy of $\pm 0.1 \mathrm{~K}$. The monitoring light is rendered monochromatic with a $200 \mathrm{~mm}$ monochromator (Jobin-Yvon H $20 \mathrm{UV}$ ) after passing through the flash cell, and its intensity is measured with a Hamamatsu R 928 photomultiplier. The re- sponse time of the detection system is $\approx 5 \mathrm{~ns}$. The multiplier signals are recorded with a Tektronix Transient Digitizer R 7912 and stored in a computer.

Transient decays with lifetimes above $\approx 100 \mu \mathrm{s}$ were recorded with a sampling flash apparatus [31] (dissipated electrical energy $200 \mathrm{~mJ}$, flash duration $1 \mu \mathrm{s}$.) The flash cells have an optical path length of $100 \mathrm{~mm}$. They are horizontally housed in a copper block and a quartz dewar with plain end windows. The copper block is cooled with a stream of cold nitrogen gas and kept constant within $0.2 \mathrm{~K}$ with a heating element which is controlled by a Pt- 100 resistance thermometer in the copper block. With this setup the temperature can be adjusted between 78 and $300 \mathrm{~K}$. The multiplier signals are recorded with a Datalab DL 905 transient recorder and stored in a computer. The signal-to-noise ratio can be improved by sampling (for details see ref. [31]).

\subsection{Data analysis}

All stored data were analysed with an Atari 1040 ST computer with arithmetic co-processor (Motorola $\mathrm{MC} 68881$ ), using a very flexible program written in " $\mathrm{C}$ " by Al-Soufi [32]. With this program it is very easy to define any analytical function with up to 10 fixed or free-running parameters and to fit this function to the experimental data with a Marquardt algorithm.

\section{Results}

As in the case of 3-hydroxyflavone [33] (and presumably also in numerous other cases where ESIPT has been studied) the photophysical properties of HBO depend very much on the purity of the sample and, in particular, of the solvent. Studies of ESIPT in non-polar solvents are perhaps most promising because the formation of intermolecular hydrogen bonds between solute and solvent is avoided. Thus, the interpretation of transient absorption spectra and of transient decay curves is less complicated. It requires, however, that the solvent does not contain water or other hydrogen bonding impurities. A critical test for such impurities is the appearance of a short-wavelength fluorescence $\left(\lambda_{\max }=370 \mathrm{~nm}\right)$ which is presumably due to solute-solvent complexation 
[27]. This emission is well separated from the Stokesshifted $1 \mathrm{~K}^{*}$ fluorescence which has a maximum at $\lambda_{\max }=490 \mathrm{~nm}$. In a carefully dried solution of HBO in an inert solvent like $\mathrm{MCH}$ or IP the fluorescence intensity ratio $R=I(370 \mathrm{~nm}) / I(480 \mathrm{~nm})$ is typically $R \leqslant 0.02$.

\subsection{Transient absorption spectra}

As pointed out already, ESIPT from ' $\mathrm{E}^{*}$ is a very rapid process and one can assume that the keto singlet state ${ }^{1} \mathrm{~K}^{*}$ is populated with a temperature-independent quantum yield of one. The intersystem crossing quantum yield $\Phi_{\mathrm{isc}}=k_{\mathrm{st}} /\left(k_{\mathrm{d}}+k_{\mathrm{f}}+k_{\mathrm{st}}\right)$ (cf. fig. 1) varies because the radiationless decay of ' $K^{*}$ depends on the temperature: $k_{\mathrm{d}}=(9 \pm 1) \times 10^{11}$ $\times \exp \left(-E_{\mathrm{d}} / R T\right) \mathrm{s}^{-1}, E_{\mathrm{d}}=15 \pm 1 \mathrm{~kJ} / \mathrm{mol}$, as we have shown in our short communication [25]. With $k_{\mathrm{st}}+k_{\mathrm{f}}=1.8 \times 10^{8} \mathrm{~s}^{-1}$ (taken from the ${ }^{1} \mathrm{~K}^{*}$ fluorescence lifetime $\tau_{\mathrm{f}}^{0}=5.6 \mathrm{~ns}$ at temperatures below $\approx 150$ $\mathrm{K}[28])$ the quantum yield $\Phi_{\mathrm{d}}(T)=k_{\mathrm{d}} /\left(k_{\mathrm{d}}+k_{\mathrm{f}}+k_{\mathrm{st}}\right)$ of the radiationless decay process is very high at room temperature: $\Phi_{\mathrm{d}}(293 \mathrm{~K})=0.95 \pm 0.05$. It is therefore difficult to measure triplet-triplet absorption spectra at higher temperatures, because $\Phi_{\text {isc }}=1-\left(\Phi_{\mathrm{d}}+\Phi_{\mathrm{f}}\right)$ is small.

We published in ref. [25] triplet spectra of $\mathrm{HBO}$ recorded at temperatures between 293 and $200 \mathrm{~K}$. In that paper we reported a strong shift of the absorption peaks within a narrow temperature range from $\lambda_{\max }=430 \mathrm{~nm}$ at $293 \mathrm{~K}$ to $\lambda_{\max }=405 \mathrm{~nm}$ at $273 \mathrm{~K}$ and below. With highly purified HBO solutions we were not able to reproduce this shift. A careful re-investigation revealed instead that the wavelength of the absorption maxima of the HBO triplet states do not change with the temperature. The results of this re-investigation are shown in fig. 2 . The spectra in this figure were determined with a conventional flash apparatus which had a time resolution of about 10 $\mu \mathrm{s}$. Within this time range the equilibrium ${ }^{3} \mathrm{~K}^{*} \rightleftarrows^{3} \mathrm{E}^{*}$ is already established. Therefore, the spectra consist of both tautomers, presumably (see below) in a concentration ratio of $1: 1$. The assignment of the $a b-$ sorption to the triplet states of HBO is unambiguous because the decay rate constants measured in absorption are identical with those determined from the dual phosphorescence decay [26].

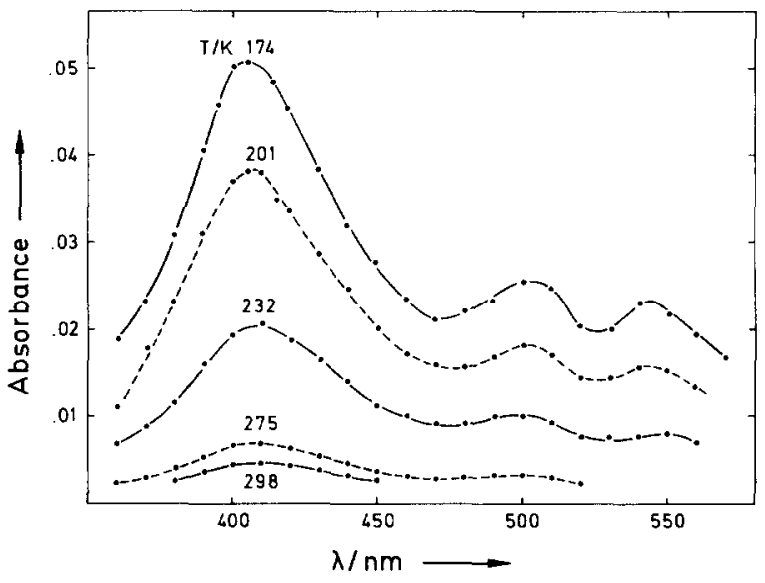

Fig. 2. Transient absorption spectra observed after flashing a solution of $1 \times 10^{-4} \mathrm{M} \mathrm{HBO}$ in MP/IP (1:1) at different temperatures, $T$, with a microsecond flash. The absorbance values were taken from decay curves extrapolated to zero time. The optical pathlength was $d=10 \mathrm{~cm}$.

\subsection{Transient kinetics}

\subsubsection{The formation of the triplet states}

Due to the rapid ESIPT reaction ${ }^{1} \mathrm{E}^{*} \rightarrow{ }^{1} \mathrm{~K}^{*}$ (cf. fig. 1 ) intersystem crossing occurs effectively only via the excited state of the keto tautomer $\left({ }^{1} \mathrm{~K}^{*} \rightarrow{ }^{3} \mathrm{~K}^{*}\right)$ because the intersystem crossing ${ }^{1} \mathrm{E}^{*} \rightarrow{ }^{3} \mathrm{E}^{*}$ cannot appreciably compete with ESIPT. Thus, within the lifetime of the Stokes-shifted fluorescence, first only the keto triplet state ${ }^{3} \mathrm{~K}^{*}$ is populated, and then the equilibrium ${ }^{3} \mathrm{~K}^{*} \rightleftarrows^{3} \mathrm{E}^{*}$ is established. This can be seen at lower temperatures in laser flash experiments. In figs. $3 a-3 c$ transient absorption curves are depicted which were recorded at different temperatures after laser flash excitation. At 55 and $110 \mathrm{~K}$ one can clearly distinguish between a fast initial rise $\left(A_{0}\right)$ of the absorbance due to ${ }^{3} \mathrm{~K}^{*}$ formation and a slower increase with a certain rate constant $\left(k_{\text {obs }}\right)$ to an absorption level $\left(A_{\infty}\right)$ which is constant within the time scale of these traces. (The decay of the transient absorption occurs more slowly, see fig. 7 below.) At $201 \mathrm{~K}$ (fig. 3a) the time scale had to be $50 \mathrm{~ns} / \mathrm{div}$ in order to resolve the rise to the final absorbance $A_{\infty}$. At this time scale the initial rise is determined by the half-life of the exciting exciplex laser pulse $(\approx 10 \mathrm{~ns})$. The ratio $A_{0} / A_{\infty}$ depends, of course, on the monitoring wavelength $\left(\lambda_{\text {obs }}\right)$ and is equal to the ratio of the extinction coef- 


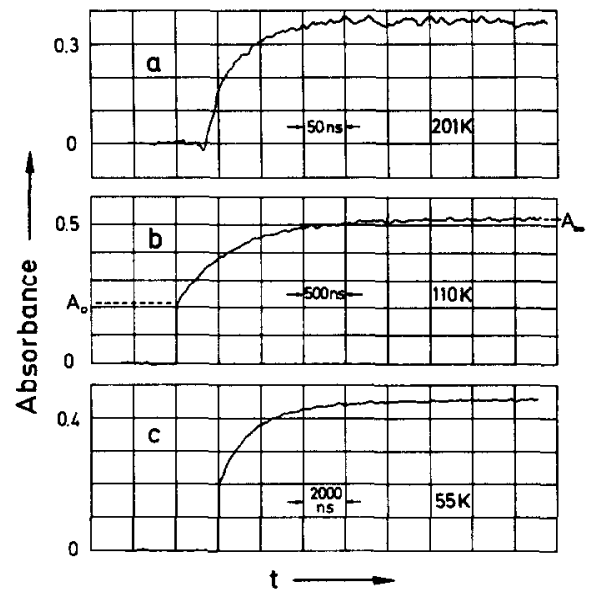

Fig. 3. Transient absorption observed after excitation of a $1 \times 10^{-4}$ $M$ solution of HBO in IP/CP (1:1) with the $248 \mathrm{~nm}$ line of an exciplex laser. Time scale and temperature as indicated in the figures. The monitoring wavelength was $\lambda_{\text {obs }}=400 \mathrm{~nm}$, the optical pathlength was $d=2 \mathrm{~cm}$.

ficients of $\mathrm{HBO}$ in the two triplet states. Below 360 $\mathrm{nm}$ we found a very narrow region within which $A_{0} /$ $A_{\infty}>1$. Instead of a growing-in, a decay from a larger absorbance $A_{0}$ to the "constant" level $A_{\infty}$ is observed in this region, as shown in fig. $4 a$. At $\lambda_{\text {obs }}=360 \mathrm{~nm}$ (fig. 4b) and around $500 \mathrm{~nm}$ (cf. fig. 5) the two triplet spectra have isosbestic points where $A_{0}=A_{\infty}$. At all other wavelengths the enol triplet state absorbs more strongly, i.e. $A_{0} / A_{\infty}<1$, like in figs. 3 and $4 \mathrm{c}$.

From the $A_{\infty}\left(\lambda_{\text {obs }}\right)$ values one obtains a transient absorption spectrum as shown in fig. 5 , which agrees very well with the spectrum in fig. 2 . From the $A_{0}\left(\lambda_{\text {obs }}\right)$ values, on the other hand, one obtains the absorption spectrum before equilibration, i.e. that of the keto triplet state alone (cf. fig. 5). Immediately after flash excitation the triplet state concentrations are $c_{0}\left({ }^{3} K^{*}\right)=c_{0}$ and $c_{0}\left({ }^{3} E^{*}\right)=0$. Since ${ }^{3} E^{*}$ and ${ }^{3} K^{*}$ have the same energy level [26] (cf. fig. 1) one may assume, that after equilibration the concentrations of the two triplet states are equal: $c_{\infty}\left({ }^{3} \mathrm{~K}^{*}\right)=c_{\infty}\left({ }^{3} \mathrm{E}^{*}\right)$. With this assumption and with $c_{\infty}\left({ }^{3} \mathbf{K}^{*}\right)+$ $c_{\infty}\left({ }^{3} \mathrm{E}^{*}\right)=c_{0}$ one can calculate the ${ }^{3} \mathrm{E}^{*}$ absorbance $A_{0}\left({ }^{3} \mathrm{E}^{*}\right)=2 A_{\infty}-A_{0}$ (dashed line in fig. 5 ) for the initial concentration $c_{0}$ in order to compare the extinction coefficients of the two triplet states.

The growing-in (rate constant $k_{\text {abs }}$ ) is mono-exponential. From traces like those shown in figs. 3a-

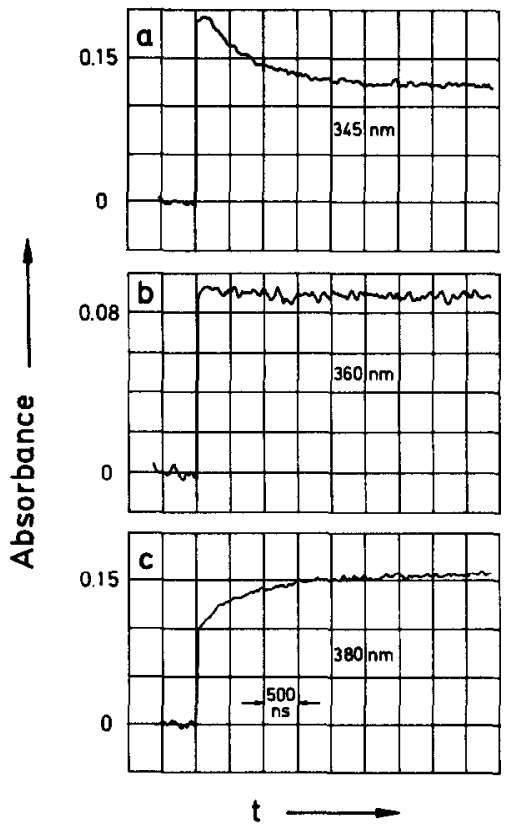

Fig. 4. Transient absorptions observed under conditions as in fig. 3. The temperature was $100.2 \mathrm{~K}$. Monitoring wavelengths as indicated in the figures.

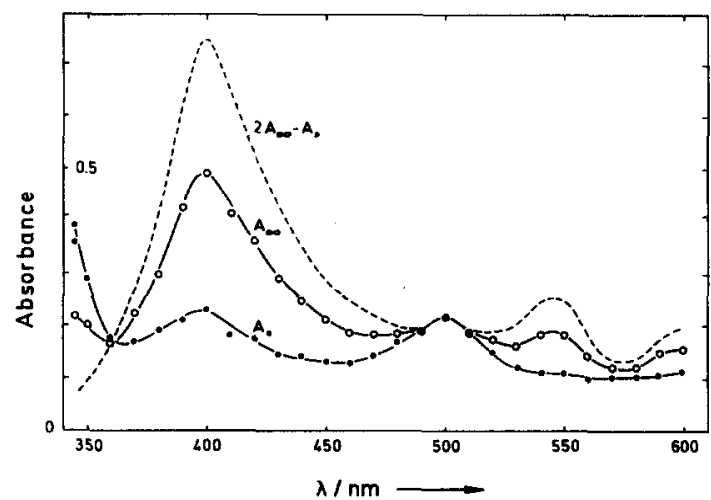

Fig. 5. Transient absorption spectra obtained from curves like those shown in fig. 4. $A_{0}$ represents the spectrum of ${ }^{3} \mathrm{~K}$ (cf. fig. 3 ), $A_{\infty}$ is the spectrum of the equilibrium mixture ${ }^{3} \mathrm{HBO}^{*}$ (see text). The dashed line represents the spectrum of ${ }^{3} \mathrm{E}^{*}$. It was calculated from the $A_{0}$ and the $A_{\infty}$ curves, assuming that the equilibrium mixture consists of equal amounts of ${ }^{3} \mathrm{E}^{*}$ and ${ }^{3} \mathrm{~K}^{*}$.

$3 \mathrm{c}$ we determined $k_{\text {obs }}(T)$ between 55 and $200 \mathrm{~K}$. An Arrhenius plot of $k_{\text {obs }}(T)$ is shown in fig. 6. It is obviously not linear and the reaction rate tends to be- 


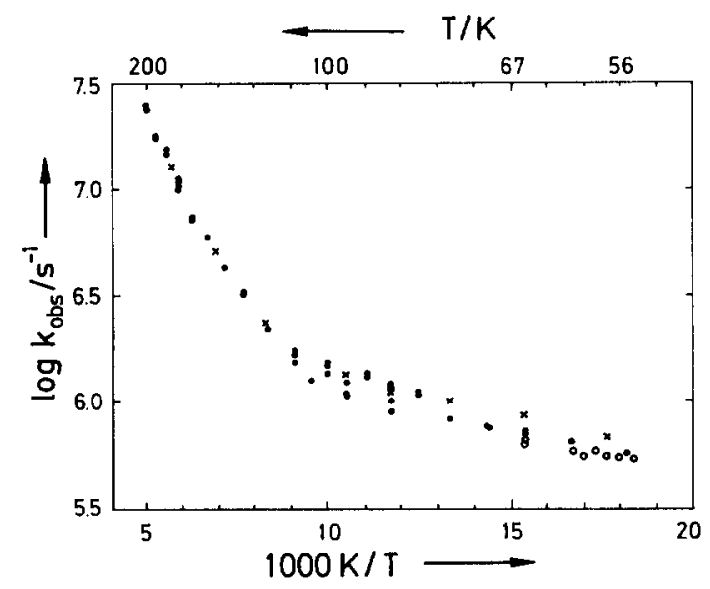

Fig. 6. Arrhenius plot of $k_{\text {obs. }}$. The rate constants $k_{\text {oba }}(T)$ were calculated from decay curves like those shown in fig. 3 . The different symbols represent results obtained with different sample preparations. Solvents used were MCH/IP (10:1) (X) and IP/ CP $(1: 1)(0,0)$.

come temperature independent below $70 \mathrm{~K}$. Above $200 \mathrm{~K}$ no reliable data are available because the intersystem crossing yield becomes low, and the time resolution of our laser flash apparatus ( $10 \mathrm{~ns}$ ) causes problems. It would be very interesting to extend the measurements below $55 \mathrm{~K}$, but we could not yet find a solvent or a solvent mixture which forms a stable gassy solution without cracks below $55 \mathrm{~K}$. The initial rise to the $A_{0}$ absorbance level could not be time-resolved with our flash apparatus.

\subsubsection{The decay of the triplet states}

The triplet state decay pattern depends strongly on the triplet state concentration due to triplet-triplet annihilation (TTA): ${ }^{3} \mathrm{HBO}^{*}+{ }^{3} \mathrm{HBO}^{*} \rightarrow{ }^{1} \mathrm{HBO}^{*}+$ ${ }^{1} \mathrm{HBO}$. (Since during the slow decay of the triplet states the equilibrium ${ }^{3} \mathrm{E}^{*} \rightleftarrows^{3} \mathrm{~K}^{*}$ is always established, we introduce for this equilibrium mixture the abbreviation ${ }^{3} \mathrm{HBO}^{*}$, and, for the excited singlet state(s), accordingly, ' ${ }^{1} \mathrm{HBO}^{*}$.) The evidence for the occurrence of TTA is two-fold. The most direct proof is the observation of a delayed fluorescence [26] which has the same spectrum as the Stokes-shifted fluorescence of $\mathrm{HBO}$ solutions under steady state illumination. This delayed fluorescence can easily be detected with standard techniques. In fact, it is so intense that the registration of the much weaker dual phosphorescence of $\mathrm{HBO}$ becomes a problem if the ${ }^{3} \mathrm{HBO}^{*}$ concentration is too high. Accordingly, the ${ }^{3} \mathrm{HBO}^{*}$ absorption decay curves are to a large extent of second order if the triplet state concentration is high and the solvent viscosity low. In fig. 7 three ${ }^{3} \mathrm{HBO}^{*}$ decay traces are shown which illustrate this fact. In fig. 7a an $\mathrm{HBO}$ solution was excited with a laser flash in a cell with an optical path length $d=2$ $\mathrm{cm}$. The initial absorbance after excitation was $A_{i}=0.28$. The insert in fig. 7 a shows a second-order plot $1 / A$ versus time which yields the rate constant $k_{2}=k_{\mathrm{TTA}} / \varepsilon d=6.75 \times 10^{4} \mathrm{~s}^{-1} \quad(\varepsilon$ is the extinction coefficient of ${ }^{3} \mathrm{HBO}^{*}$ at the monitoring wavelength ).

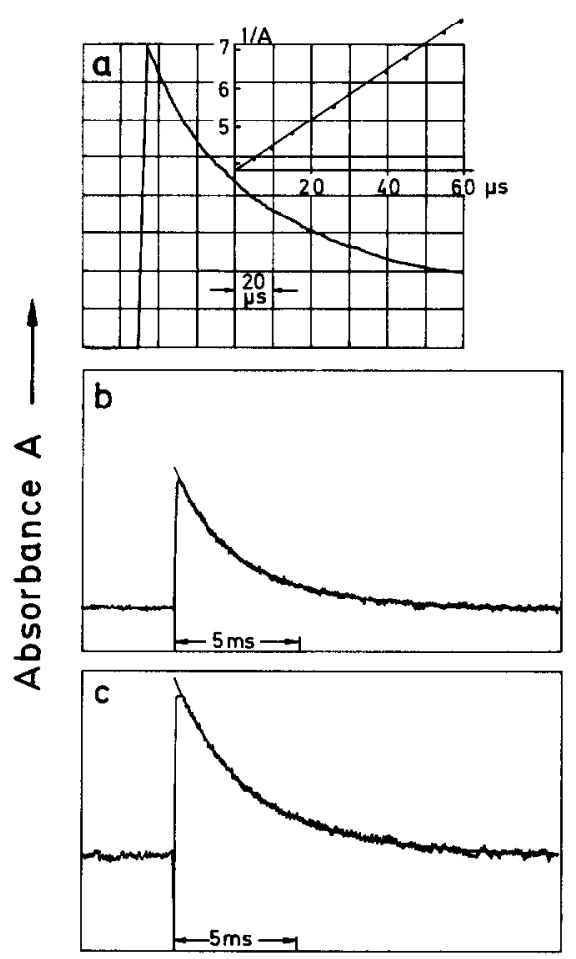

Fig. 7. Transient decay curves observed after excitation of a $1 \times 10^{-4} \mathrm{M}$ solution of $\mathrm{HBO}$ in $\mathrm{MCH}$ at $T=201 \mathrm{~K}$. (a) Excitation with the $248 \mathrm{~nm}$ line of a focused exciplex laser. The optical pathlength was $d=2 \mathrm{~cm}$, the absorbance at $t=0$ was $A_{\mathrm{i}}=0.28$. The insert shows a second-order plot of the decay trace. Note, that the decay is by no means complete. (b) and (c): Excitation with a conventional flash, dissipated electrical energy $\approx 200 \mathrm{~mJ}$ (b) and $\approx 100 \mathrm{~mJ}(\mathrm{c}) ; 16$ decay curves were sampled and averaged. The optical pathlength was $d=10 \mathrm{~cm} ; A_{\mathrm{i}}=0.011$ (b); $A_{\mathrm{i}}=0.0056$ (c). The smooth lines were calculated with the parameters $k_{\mathrm{l}}=2.77 \times 10^{2} \mathrm{~s}^{-1} ; k_{2} / \varepsilon d=1.25 \times 10^{4} \mathrm{~s}^{-1}$ (b) and $k_{1}=2.49 \times 10^{2} \mathrm{~s}^{-1} ; k_{2} / \varepsilon d=1.50 \times 10^{4} \mathrm{~s}^{-1}$ (c). 
One can use the rate constants $k_{2}(T)$ of this TTA process to estimate the value of $\varepsilon$, assuming that $k_{\mathrm{TTA}}$ is independent of the solute. By comparing the TTA rates of $\mathrm{HBO}$ with those of anthracene (whose triplet state extinction coefficients are known) in the solvents $\mathrm{MCH}$ and IP between 133 and $296 \mathrm{~K}$, we obtained [25] the value $\varepsilon=(4 \pm 1) \times 10^{3} \mathrm{M}^{-1} \mathrm{~cm}^{-1}$ at the absorption maximum $\lambda_{\max }=405 \mathrm{~nm}$. In figs. $7 \mathrm{~b}$ and $7 \mathrm{c}$ an $\mathrm{HBO}$ solution was excited with a conventional flash in a cell with optical pathlength $d=10 \mathrm{~cm}$. The initial absorbances were $A_{\mathrm{i}}=0.011$ (fig. $7 \mathrm{~b}$ ) and $A_{\mathrm{i}}=0.0056$ (fig. $7 \mathrm{c}$ ), i.e. the initial triplet concentration ratio in figs. $7 \mathrm{a}-7 \mathrm{c}$ is $\mathrm{a}: \mathrm{b}: \mathrm{c}=250: 2: 1$. The smooth lines in figs. $7 \mathrm{~b}$ and $7 \mathrm{c}$ were calculated assuming a mixed order decay $-\mathrm{d} A / \mathrm{d} t=k_{1} A+\left(k_{\mathrm{TTA}}\right)$ $\varepsilon d) A^{2}$, with $A=\varepsilon\left[{ }^{3} \mathrm{HBO}^{*}\right] d$ and the parameters $k_{1}$ and $k_{\mathrm{TTA}} / \varepsilon d$ whose values are given in the caption to fig. 7 .

Details of the results of such evaluations can be found in ref. [25]. We want to emphasize here that the assumption of triplet-triplet absorption is sufficient to explain the drastically different decay patterns of the transient absorptions, found in our flash experiments with high-intensity laser excitation, causing large TTA contributions, and low-intensity conventional flash excitation. In particular, we have no experimental evidence for a transient absorption of the keto ground-state tautomer ${ }^{1} \mathrm{~K}$. Based on laserexcitation absorption and emission experiments Itoh et al. [34] proposed that ' $\mathrm{K}$ in $\mathrm{MCH}$ at room temperature has a lifetime of $260 \mathrm{~ns}$ and an absorption maximum at $\lambda_{\max }=420 \mathrm{~nm}$. This proposal would imply a proton back-transfer ${ }^{1} \mathrm{~K} \rightarrow{ }^{1} \mathrm{E}$ which would be very slow compared to ESIPT. We suspect that $\mathrm{H}$ bonding solvent impurities caused the appearance of the transient absorption with a lifetime of $260 \mathrm{~ns}$. (The ratio $R$ of the fluorescence intensities (see section 3 ) was very high in these experiments (fig. 1 in ref. [34] ), namely $R=0.18$.) That very small traces of water can cause artefacts is documented by the following observation. We prepared a carefully dried and degassed solution of HBO in MP : IP $(1: 1)$ as described in section 2.2. In fig. 8a a transient absorption trace is depicted which was obtained after exciting this solution at $296 \mathrm{~K}$ with a $248 \mathrm{~nm}$ laser flash. The instantaneous increase in absorption is due to the formation of ${ }^{3} \mathrm{HBO}^{*}$, monitored at $400 \mathrm{~nm}$. Evidently, no short-lived absorption with a lifetime of

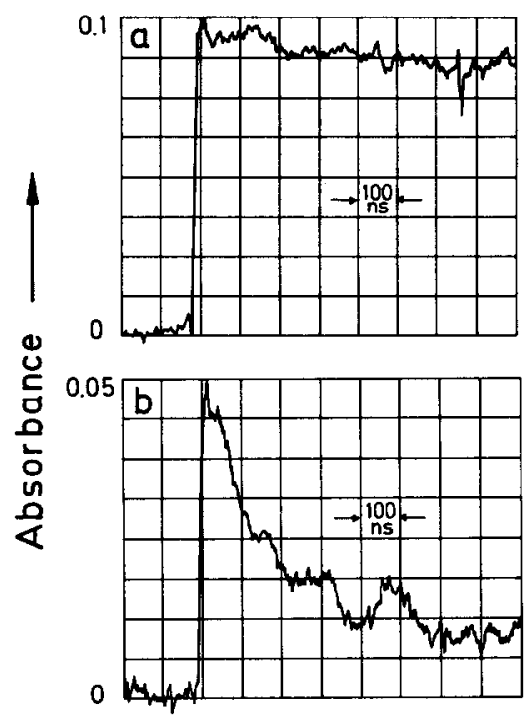

Fig. 8. Transient decay of a $1 \times 10^{-4} \mathrm{M}$ solution of $\mathrm{HBO}$ in $\mathrm{MCH}$ at $293 \mathrm{~K}$ flashed with the $248 \mathrm{~nm}$ line of an exciplex laser. (a) Normal cell assembly; (b) after sealing off a part of the assembly (see text, section 3.2.2.).

$260 \mathrm{~ns}$ is detectable. For technical reasons, we had to seal off the storage vessel from the cell assembly after this experiment. This was done with the solution kept at $77 \mathrm{~K}$. After this procedure the very same solution exhibited the short-lived transient absorption shown in fig. 8b. We have little doubt that this drastic change is due to traces of water which were liberated from the pyrex glass tubing during the sealing-off procedure. Normally, such traces are to a large extend pumped away if the cells are sealed off from an open vacuum line, but in the case mentioned above these traces were partly trapped in the cooled solution. We describe this experiment here are some length because it demonstrates that ESIPT experiments in nonpolar solvents have to be carried out under well controlled conditions.

From traces like those shown in figs. $7 \mathrm{~b}$ or $7 \mathrm{c}$ the first-order rate constant of the ${ }^{3} \mathrm{HBO}^{*}$ triplet decay $\left(k_{1}\right)$ in MP/IP was determined between 98 and 140 $\mathrm{K}$ (table 1 ). In this temperature range the solvent mixture MP/IP is still liquid, but its viscosity, $\eta(T)$ [35] (the experimental method is described in ref. [36]), varies by 5 orders of magnitude. Nevertheless, the first-order decay rate constant $k_{1}$ has within experimental error the same value. 
Table 1

Rate constants, $k_{1}$, of the ${ }^{3} \mathrm{HBO}^{*}$ decay and viscosities, $\eta$, of the solvent mixture MP/IP $(1: 1)$ at different temperatures, $T$. The values in parentheses are taken from ref. [26]. They were determined from phosphorescence decay curves measured with a different sample which was less rigorously dried

\begin{tabular}{rll}
$T(\mathrm{~K})$ & $k_{1}\left(\mathrm{~s}^{-1}\right)$ & $\eta(\mathrm{cP})$ \\
\hline 98.1 & $82 \pm 1(83)$ & $1.0 \times 10^{6}$ \\
101.1 & $82 \pm 1$ & $1.7 \times 10^{5}$ \\
103.3 & $82 \pm 1$ & $5.70 \times 10^{3}$ \\
111.1 & $86 \pm 1$ & $1.78 \times 10^{3}$ \\
121.3 & $90 \pm 9(116)$ & $1.3 \times 10^{2}$ \\
139.7 & $84 \pm 16(192)$ & $1.6 \times 10^{1}$ \\
\hline
\end{tabular}

\subsubsection{Isotope effects}

So far, only a few experiments have been carried out with $\mathrm{DBO}$, where the proton of the $\mathrm{OH}$ group of $\mathrm{HBO}$ is replaced by a deuteron. By dissolving HBO in $\mathrm{CH}_{3} \mathrm{OD}$, this exchange is easily accomplished (it has been verified by mass spectrometry). However, it is much more difficult to replace the alcohol afterwards by an inert solvent and to avoid re-exchange in diluted DBO solutions (e.g. $\mathrm{DBO}+\mathrm{H}_{2} \mathrm{O} \rightarrow \mathrm{HBO}$ $+\mathrm{DHO}$ ) during this procedure. (If $5 \mathrm{ml}$ of a $10^{-4} \mathrm{M}$ solution of DBO are contaminated with water (e.g. from the glass walls of the flash cell assembly) $0.1 \mathrm{mg}$ $\mathrm{H}_{2} \mathrm{O}(20 \mathrm{ppm})$ corresponds to a ten-fold excess in water concentration!) The procedure which finally led to reliable results is described in section 2.2.

The main goal of the experiments with DBO was to find out whether the rate of the equilibrium reaction ${ }^{3} \mathrm{~K} \rightleftarrows{ }^{3} \mathrm{E}^{*}$ of DBO (rate constant $k_{\mathrm{obs}}^{\mathrm{D}}$ ) is smaller than that of HBO $\left(k_{\text {obs }}^{\mathrm{H}}\right)$. Such an isotope effect, $I=k_{\mathrm{obs}}^{\mathrm{H}} / k_{\mathrm{obs}}^{\mathrm{D}}$, is to be expected if the rate of the proton- (or hydrogen-) transfer reaction is appreciably influenced by a tunnel effect.

Although the photophysical properties of DBO have still to be investigated more thoroughly, the first experiments, carried out very recently, indicate that, indeed, the triplet states of DBO equilibrate more slowly than those of HBO. The observed isotope effect is temperature dependent.

\section{Discussion}

For the discussion of the results presented in section 3 , the recently reported [26] dual phosphores- cence emitted from the two triplet states, ${ }^{3} \mathrm{~K}^{*}$ and ${ }^{3} \mathrm{E}^{*}$, of $\mathrm{HBO}$ is an important observation. It makes, together with the additionally observed delayed fluorescence, the assignment of the absorption spectra in fig. 2 to the triplet states of HBO unambiguous. The agreement of the transient absorption spectra in fig. 2 with the $A_{\infty}$ spectrum in fig. 5 links the microsecond with the nanosecond flash experiments: the final absorptions in fig. 3 originate from the equilibrated mixture of the triplet states ${ }^{3} \mathrm{~K}^{*}$ and ${ }^{3} \mathrm{E}^{*}$. This mixture, in turn, emits the dual phosphorescence and decays as shown in fig. 7. The initial, rapid rise in the traces of figs. 3 and 4 we assign to the absorption of the keto triplet state because of the kinetically identical decay below, and the growing-in above the isosbestic point at $360 \mathrm{~nm}$ (cf. fig. 4). It shows clearly that the two transients are related. Since, due to the very rapid ESIPT reaction in the first excited singlet state, the direct formation of ${ }^{3} E^{*}$ from ${ }^{~} E^{*}$ can be neglected, it is logical to assign the initial absorption to ${ }^{3} \mathrm{~K}^{*}$. Its risetime should range from $\approx 200 \mathrm{ps}$ at room temperature to $\approx 6 \mathrm{~ns}$ below $160 \mathrm{~K}$, like the decay time of the Stokes-shifted fluorescence, because both have the same origin (cf. fig. 1). With a picosecond laser flash apparatus it should be easy to compare the rates of these two processes.

In our flash experiments the equilibration reaction starts far away from equilibrium, i.e. under the condition $c_{0}\left({ }^{3} \mathrm{~K}^{*}\right)=c_{0}$ and $c_{0}\left({ }^{3} \mathrm{E}^{*}\right)=0$ and the experimentally observed rate constants, $k_{\text {obs }}(T$ ) (cf. fig. 6) are the sums of the two rate constants $k_{\mathrm{tt}}^{\mathrm{K}}$ and $k_{\mathrm{tt}}^{\mathrm{E}}$ (cf. fig. 1) of the equilibrium ${ }^{3} \mathrm{~K}^{*} \rightleftarrows^{3} \mathrm{E}^{*}$. This is an interesting situation, because it allows us to study kinetically the establishment of an equilibrium between two iso-energetic species, whereby at time zero (on the time scale at which the equilibration occurs) only one partner is present. During the equilibration $\mathrm{N}-\mathrm{H}$ - and $\mathrm{O}-\mathrm{H}$ bonds are broken and formed and a hydrogen atoms migrates between the two hetero atoms, presumably in a symmetrical double-minimum potential. Since $k_{\mathrm{obs}}^{\mathrm{H}}(T)$ becomes nearly temperature independent below $70 \mathrm{~K}$ and since the Arrhenius plot of $k_{\mathrm{obs}}^{\mathrm{H}}$ (fig. 6) is by no means linear, hydrogen tunnel effects play obviously an important role. This is corroborated by the observed, temperature-dependent, isotope effect $I(T)=k_{\mathrm{obs}}^{\mathrm{H}} / k_{\mathrm{obs}}^{\mathrm{D}}$ which amounts to $I=30$ at $200 \mathrm{~K}$ and $I \geqslant 300$ at $100 \mathrm{~K}$, according to our preliminary results. 
HBO then is one of the first examples where in fluid solution a hydrogen tunnel effect in an electronically excited state has been observed. (A second example (DMTK) is mentioned below. Excited state tunneling in doped single crystals has been studied by Stehlik and co-workers [37].) From a theoretical point of view the equilibration ${ }^{1} \mathrm{~K}^{*} \rightarrow{ }^{3} \mathrm{~K}^{*} \rightleftarrows^{3} \mathrm{E}^{*}$ may become a very interesting reaction. Firstly, it will most probably be possible to follow the reaction of the deuterated compound DBO down to temperatures where the observed rate constants, $k_{\mathrm{obs}}$, are very close to the temperature-independent value, as is already the case with $\mathrm{HBO}$ at $55 \mathrm{~K}$ (cf. fig. 6). If the finite hydrogen and deuterium tunneling rate constants are both known, it may become easier to calculate quantum mechanically the barrier height and width of the double-minimum potential. In other systems where tunnel and isotope effects have been observed [38], the rate constants of the deuterated compounds become so small with decreasing temperature that the temperature-independent region is experimentally inaccessible. Secondly, it should be possible to make the double-minimum potential asymmetric by tuning the energy difference between the two triplet states with the introduction of appropriate substituents into HBO. Preliminary experiments with $2-\left(2^{\prime}\right.$-hydroxy5 '-methylphenyl)benzoxazole indicate that the introduction of the 5 -methyl group has this effect.

With the detection of ESIPT in the triplet state, another interesting question arises, namely why the energy barrier between ${ }^{3} \mathrm{E}^{*}$ and ${ }^{3} \mathrm{~K}^{*}$ is much higher than that between ${ }^{1} \mathrm{E}^{*}$ and ${ }^{1} \mathrm{~K}^{*}$. The difference is presumably quite large, because ESIPT in the triplet state is very much slower than in the singlet manifold. In fig. 9 we show, on a compressed scale, with heavy lines the experimental results of fig. 6 and the preliminary results obtained with the deuterated compound. The broken line of the OD curve is an extrapolation into a region which will be experimentally accessible. The two light lines, however, are an "artist's view" of the high-temperature region, assuming a frequency factor of $10^{13} \mathrm{~s}^{-1}$ for the $H$ and $D$ transfer. This extrapolation is meant to demonstrate that it will not be easy to even estimate the barrier height of the ESIPT reaction in the triplet state. But it is presumably reasonable to assume that the transfer within the triplet manifold is an allowed reaction with a frequency factor between $10^{12}$ and $10^{14} \mathrm{~s}^{-1}$. The barrier height will

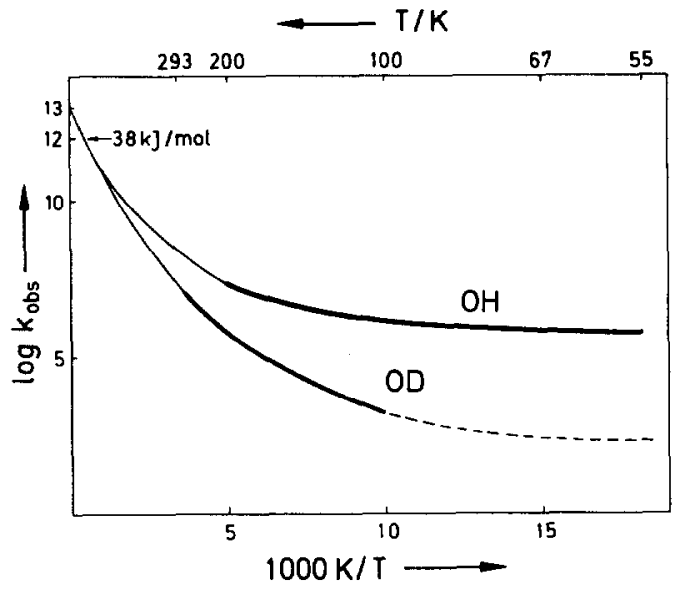

Fig. 9. Arrhenius plot of $k_{\mathrm{obs}}^{\mathrm{H}}$ from fig. 6 and $k_{\mathrm{obs}}^{\mathrm{D}}$ (see text).

then lie between 30 and $50 \mathrm{~kJ} / \mathrm{mol}$, which is certainly a much higher value than for the barrier between ${ }^{~} \mathrm{E}^{*}$ and ' $\mathrm{K}^{*}$, if one exists at all. (From the fact that no ${ }^{1} E^{*} \rightarrow{ }^{1} E$ fluorescence is observed even at very low temperatures, one may conclude that no barrier exists or that it is penetrated at low temperatures by tunneling.)

We would like to mention in this context that with the ketone 5,8-dimethyltetralone (DMTK) hydrogen and deuterium transfer rate constants were determined whose values are strikingly similar to those shown in fig. 9. In this case the ketone is the stable form, which enolizes [39] in the excited triplet state, yielding the enol, DMTE, whereby a hydrogen (or deuterium) atom is transferred from the $C$ atom of the methyl group to the $\mathrm{O}$ atom of the keto group $[32,40]$ :

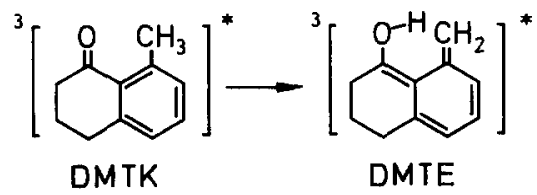

In fig. 10 an attempt is made to picture, in a simple way, the difference between the singlet and triplet manifold of HBO. The electronic configuration of the "keto form" is prepared from the enol, ' $\mathrm{E}$, during the absorption of a photon followed by the rate determining step of the transfer of the proton to the negatively charged nitrogen atom, yielding ${ }^{\prime} K^{*}$. The reverse process in the singlet ground state $\left({ }^{1} \mathrm{~K} \rightarrow{ }^{1} \mathrm{E}\right)$ 
takes place in a similar fashion; it should therefore also be very rapid. (The energy gap between keto and enol form (cf. fig. 1) in the ground state is even larger $\left(4900 \mathrm{~cm}^{-1}\right)$ than in the excited state $\left(2100 \mathrm{~cm}^{-1}\right)$.)

In the triplet state, wc assume that the neutral resonance structures shown in fig. 10 are more strongly represented than the zwitterionic structures drawn for the singlet states. In fig. 10 we therefore distinguish between hydrogen and proton transfer, and we suggest that the hydrogen transfer between the uncharged hetero atoms in the triplet state is slower than the proton transfer in the singlet states, where zwitterionic structures prevail.

The decay rate of the triplet states at low concentrations (cf. fig. 7) is governed by temperature-independent radiationless intersystem crossing to the singlet ground state. (TTA contributions are almost negligible.) The constant values given in table 1 show that below $140 \mathrm{~K}$ adventitious quenching can no longer be important, because the solvent viscosity varies by almost five orders of magnitude. The measured rate constant $k_{1}=82 \mathrm{~s}^{-1}$ results, of course, from the decay of both triplet states, because during the decay the equilibrium ${ }^{3} \mathrm{~K}^{*} \rightleftarrows{ }^{3} \mathrm{E}^{*}$ remains established. The multi-exponential decay of the dual phosphorescence in a glassy solution of HBO in MP/IP at $76 \mathrm{~K}$ was used by Nickel and Rodrigues Pietro [29] to estimate the individual rate constants. They found that ${ }^{3} \mathrm{~K}^{*}$ decays $30-60$ times faster than ${ }^{3} \mathrm{E}^{*}$. The much faster decay of ${ }^{3} \mathrm{~K}^{*}$ is to be expected because the energy difference between ${ }^{3} \mathrm{~K}^{*}$ and ${ }^{1} \mathrm{~K}\left(17500 \mathrm{~cm}^{-1}\right)$ is
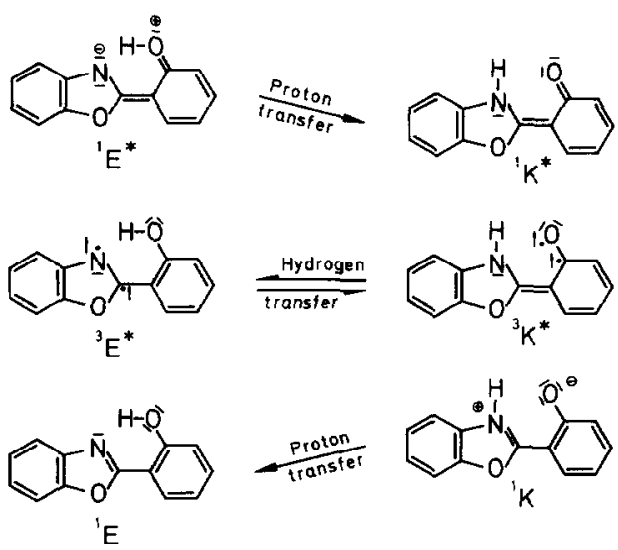

Fig. 10. Electronic resonance structures assumed to prevail in the electronic states indicated (cf. fig. 1 ). smaller than the difference between ${ }^{3} \mathrm{E}^{*}$ and ${ }^{1} \mathrm{E}$ $\left(22400 \mathrm{~cm}^{-1}\right)$.

\section{Conclusion}

HBO has very interesting photophysical properties, both in the singlet and in the triplet manifold. With the detection and characterization of its dual phosphorescence it was possible to determine the relative energies of the Förster cycle shown in fig. 1. No convincing experimental evidence for a long-lived keto ground state tautomer, ${ }^{1} \mathrm{~K}$, has so far been presented. Our flash experiments indicate that ' $\mathrm{K}$ does not accumulate in measurable concentrations. The kinetic analysis of the equilibration ${ }^{1} \mathrm{~K}^{*} \rightarrow{ }^{3} \mathrm{~K}^{*} \rightleftarrows^{3} \mathrm{E}^{*}$, investigated between 55 and $220 \mathrm{~K}$, showed that at lower temperatures hydrogen tunnel effects determined the rate of the tautomerization in the triplet state. It is to be expected that the isotope effect of this reaction can be studied much more completely than in other systems, because the expected rate constants should have values which lie in a region, which is experimentally easily accessible. The barrier for the hydrogen transfer is in the triplet state evidently much higher than in the singlet state. Proton transfer in the singlet state and hydrogen transfer in the triplet state is suggested as a possible cause for this difference.

\section{Acknowledgement}

This investigation was supported by the Deutsche Forschungsgemeinschaft (Sonderforschungsbereich 93, "Photochemie mit Lasern", Teilprojekt D2). AM thanks the Max-Planck-Gesellschaft for the award of a research fellowship. We thank Professor A. Weller for support of this work and for helpful discussions, Dr. W. Kühnle for the HPLC purification of HBO and the mass spectra of DBO, Dr. B. Nickel for critical reading of the manuscript, Mr. W. Al-Soufi for help with computer problems and Mr. J. Plotzki for technical assistance.

\section{References}

[1] A. Weller, Z. Elektrochem. 60 (1956) 1144. 
[2] M.H. van Benthem and G.D. Gillispie, J. Phys. Chem. 88 (1984) 2954.

[3] U. Brackmann, N.P. Ernsting, D. Ouw and K. Schmitt, Chem. Phys. Letters 110 (1984) 319.

[4] G. Woessner, G. Goeller, P. Kollat, J.J. Stezowski, M. Hauser, U.K.A. Klein and H.E.A. Kramer, J. Phys. Chem. 88 (1984) 5544.

[5] A. Mordziński, A. Grabowska and K. Teuchner, Chem. Phys. Letters 11 (1984) 383.

[6] N.P. Ernsting, J. Phys. Chem. 89 (1985) 4932.

[7] A. Mordziński and W. Kühnle, J. Phys. Chem. 90 (1986) 1455.

[8] K.P. Ghiggino, A.D. Scully and I.H. Leaver, J. Phys. Chem. 90 (1986) 5089.

[9] T. Nishiya, S. Yamauchi, N. Hirota, M. Baba and I. Hanazaki, J. Phys. Chem. 90 (1986) 5730.

[10] R.S. Becker, C. Lenoble and A. Zein, J. Phys. Chem. 91 (1987) 3509.

[11] S.I. Druzhinin, S.A. Krashakov, I.V. Troyanovsky and B.M. Uzhinov, Chem. Phys. 116 (1987) 231.

[12] N.P. Ernsting, A. Mordziński and B. Dick, J. Phys. Chem. 91 ( 1987$) 1404$.

[13] B. Dick, Ber. Bunsenges. Physik. Chem. 91 (1987) 1205.

[14] G. Goeller, J. Rieker, A. Maier, J.J. Stezowski, E. Daltrozzo, M. Neureiter, H. Port, M. Wiechmann and H.E.A. Kramer, J. Phys. Chem. 92 (1988) 1452.

[15] D. Huppert, M. Gutman and K.J. Kaufmann, Advan. Chem. Phys. 47 (1981) 643.

[16] G.R. Fleming, Chemical Applications of Ultrafast Spectroscopy (Oxford Univ. Press, Oxford, 1986) p. 200.

[17] F. Hibbert, Advan. Phys. Org. Chem. 22 (1986) 146.

[18] E.M. Kosower and D. Huppert, Ann. Rev. Phys. Chem. 37 (1986) 127.

[19] H. Shizuka, M. Machii, Y. Higaki, M. Tanaka and I. Tanaka, J. Phys. Chem. 89 (1985) 320.

[20] S.R. Flom and P.F. Barbara, J. Phys. Chem. 89 (1985) 4489.

[21] T. Elsaesser and W. Kaiser, Chem. Phys. Letters 128 (1986) 231.

[22] T. Elsaesser, B. Schmetzer, M. Lipp and R.J. Bäuerle, Chem. Phys. Letters 148 (1988) 112.
[23] F. Laermer, T. Elsaesser and W. Kaiser, Chem. Phys. Letters 148 (1988) 119.

[24] A. Grabowska, A. Mordziński, N. Tamai and K. Yoshihara, Chem. Phys. Letters 153 (1988) 389.

[25] A. Mordziński and K.H. Grellmann, J. Phys. Chem. 90 (1986) 5503.

[26] M.F. Rodrigues Prieto, B. Nickel, K.H. Grellmann and A. Mordziński, Chem. Phys. Letters 146 (1988) 387.

[27] G.J. Woolfe, M. Melzig, S. Schneider and F. Dörr, Chem. Phys. 77 (1983) 213, and references therein.

[28] A. Mordziński and A. Grabowska, Chem. Phys. Letters 90 (1982) 122.

[29] B. Nickel and M.F. Rodrigues Prieto, Chem. Phys. Letters 146 (1988) 393.

[30] A. Eychmüller, K.H. Grellmann and H. Dräger, Rev. Sci. Instr. 56 (1985) 2333.

[31] K.H. Grellmann and H.G. Scholz, Chem. Phys. Letters 62 (1979) 64.

[32] W. Al-Soufi, Masters Thesis, University of Göttingen, FRG (1988).

[33] D. McMorrow and M. Kasha, J. Phys. Chem. 88 (1984) 2235.

[34] M. Itoh and Y. Fujiwara, J. Am. Chem. Soc. 107 (1985) 1561.

[35] B. Nickel and $H$. Lesche, private communication.

[36] H. Lesche, D. Klemp and B. Nickel, Z. Physik. Chem. 141 (1984) 239.

[37] M. Tietje, C. von Borczyskowski, B. Prass and D. Stehlik, Chem. Phys. Letters 127 (1986) 475, and references therein.

[38] G. Bartelt, A. Eychmüller and K.H. Grellmann, Chem. Phys. Letters 118 (1985) 568;

G. Brunton, D. Griller, L.R.C. Barclay and K.U. Ingold, J. Am. Chem. Soc. 98 (1976) 6803.

[39] J. Scaiano, Chem. Phys. Letters 73 (1980) 319, and references therein.

[40] K.H. Grellmann, W. Al-Soufi and A. Eychmüller, to be published. 